\title{
STIFFNESS AND FATIGUE OF ASPHALT MIXTURES FOR PAVEMENT CONSTRUCTION
}

Juraj ŠRÁMEK ${ }^{1 *}$

\section{Abstract}

The quality of a road is affected by its correct design, the appropriate use of materials, the effects of the climate, and the technological discipline. The deformation properties and fatigue of asphalt layers are important for the design and assessment of semi-rigid and flexible pavements. The assessment of deformation properties is performed by means of a dynamic impact test and the fatigue life of a particular asphalt mixture. An evaluation of the fatigue life is based on decreases in resistance or increases in deformations in different binders and mixtures. The test methods for the design and control of pavement construction materials determine the basic conditions valid for flexible matter. The Two-Point Bending Test was used for determining the deformation characteristics and the fatigue of asphalt mixtures at the Department of Construction Management in Zilina.

\section{Address}

1 University of Zilina, Faculty of Civil Engineering, Department of Construction Management

* Corresponding author: juraj.sramek@fstav.uniza.sk

\section{Key words}

- Asphalt mixture,

- Deformation properties,

- Complex modulus,

- Fatigue,

- Recycling.

\section{INTRODUCTION}

Deformation properties, resistance to deformation, and fatigue performance of asphalt mixtures have a significant effect on the operational performance of asphalt pavements. When a pavement is being constructed, the asphalt serves as a binder for the mineral aggregates of the surfacing layer. The mechanical properties of an asphalt mixture are mostly affected by the properties of the asphalt binder applied. With regard to the mixing process, an asphalt binder must be fluid enough at high temperatures of about $160{ }^{\circ} \mathrm{C}$ to create a homogenous coating of the aggregate. The local climate plays a role as the binder has to maintain the prescribed amount of stiffness at the highest summer temperature to resist rutting deformations, but has to remain flexible enough at low temperatures during the winter season. The assessment of deformation properties is performed by means of a dynamic impact test and the fatigue life of a particular asphalt mixture. An evaluation of the fatigue life is based on decreases in resistance or increases in deformations in different binders and mixtures. The materials used in the structural layers of pavement are assessed following the qualitative conditions of the European stand- ard STN EN 13 108-1: Asphalt mixtures, Material specifications. Part 1: Asphalt concrete defines the term "functional conditions" (STN EN 13 108-1, 2016). The functional conditions are the properties of asphalt mixtures which are defined by tests (fatigue, rutting, triaxial tests). It is possible to use several types of tests to measure the complex modulus and fatigue in accordance with the European standard (EN 12697-26, 2012), (EN 12697-24, 2012). The tests differ as to the load and intensity applied. This article describes the measurement of deformation properties by a two-point bending test. The design of asphalt concrete and the required properties of the constituent materials and their mixing ratios, are of tremendous significance and should be implemented with consideration given to the whole life cycle of those materials and the final construction. Conformity with the requirements for the long-term performance of embedded materials is the general objective of the Life Cycle Assessment (LCA). Therefore, the material properties need to be evaluated during the assessment with consideration given to the whole service life, from the point of their embedding in the construction until their disposal or recycling (Schlosser at. al, 2013), (Mikolaj at. al., 2016). 


\section{DEFORMATION PROPERTIES AND FATIGUE}

The design of an asphalt mixture in terms of the material and mixture ratios must ensure that the criteria for withstanding all adverse conditions through the whole life cycle under actual operating conditions are met. For the LCA of basic, normatively prescribed parameters of asphalt mixtures, it is necessary to analyse the deformation properties as well as the fatigue resistance and life expectancy derived from it. The parameters are defined in concordance with the stresses to which the asphalt mixture material is subjected in actual life service conditions. The operational capability of a road is substantially dependent on the deformation and strength characteristics of materials that form the wearing course of flexible pavements. The basic deformation characteristics include the modulus of elasticity, deformation modulus, modulus of stiffness, creep modulus and Poisson's ratio. The basic strength characteristics are stability, compressive strength, flexural strength and splitting tensile strength (Mikolaj at. al., 2016), (Mikolaj at. al., 2017), (Schlosser at. al., 2016).

The test methods for the design and control of pavement construction materials determine the basic conditions valid for flexible matter. Materials in terms of deformation properties are divided into solid, viscous and plastic materials. The activity of the majority of road construction materials loaded short or long term is expressed by the Boltzmann theory of linear viscoelastic materials, which reflects the effects of repeated stress (fatigue). Most road construction materials are characterized as linear viscoelastic matter, which is simplified in the Boltzmann theory by a mechanical model consisting of a system of springs (flexibility) and silencers (viscosity), which are located behind or next to each other and which may be deformed by reversible (immediate or delayed) or variable permanent deformations (Šrámek, 2015), (Žák at. al., 2014), (Remišová at. al., 2014), (Ďurčanská at. al., 2013).

The complex modulus is the ratio of tension and deformation at steady, harmonically variable oscillations in consideration of their mutual time shifts.

$$
E^{*}=\frac{\sigma_{0}}{\varepsilon_{0}}=\left(E_{1}^{2}+E_{2}^{2}\right)^{\frac{1}{2}}
$$

The complex modulus is measured on samples exposed to shortterm alternating harmonic loads. It conveys the proportion of the maximum amplitude of excitation tension $\left(\sigma_{0}\right)$, maximum amplitude of the induced deformation $\left(\varepsilon_{0}\right)$, and phase shifts of their amplitudes $(\varphi)$. The stress, the load, which varies sinusoidally over time, is applied to the elements of the linear viscoelastic material. The strain varies over time with the same frequency as the stress, but it lags behind the phases. The values measured for particular mixtures are graphically presented on the chart shown in Figure 1. A graphical representation of the measurements and complex modulus evaluation is shown in Figure 2.

An accurate assessment of the fatigue life of asphalt mixtures depends on the criteria used in the fatigue analysis. Fatigue is the reduction of the strength of a material under repeated loading when compared to the strength under a single load. The value $\varepsilon_{6}=1 \cdot 10^{6}$ cycles (in $\mathrm{m} / \mathrm{m}$ ) is the strain corresponding to $10^{6}$ cycles (Schlosser at. al., 2013).

According to the Slovak dimensioning method, the amount of fatigue is given by:

$$
S=a-b \cdot \log N_{i}
$$

where: $\quad a, b$ - fatigue coefficients,

$N_{i}$ - number of load cycles.
Our tests of the complex modulus and fatigue were carried out at the laboratory of the Department of Construction Management of the University of Žilina. Bending tests are widely used for measuring the stiffness modulus and assessing the fatigue resistance of asphaltic paving materials. The two-point bending test on trapezoidal specimens is, arguably, the most repeatable and reproducible bending test method detailed in the relevant (EN 12697-26, 2012), (EN 12697-24, 2012). In this test the specimen is mounted as a vertical cantilever. The base is fixed, and the top is moved sinusoidally with a constant displacement amplitude. The trapezoidal shape ensures that the maximum values of the bending stress and strain occur away from the ends of the specimen, where there are likely to be stress concentrations.

Two trapezoidal specimens are tested simultaneously with Cooper Technology equipment and the stiffness modulus can be determined at a range of frequencies and temperatures. The specimens are subjected In the fatigue test to a constant strain amplitude at a selected frequency and temperature until the stiffness modulus decreases to a user-selected target level (normally 50 percent of its initial value).

The equipment (Figure 3 ) works with a constant deviation within temperature from -20 to $30{ }^{\circ} \mathrm{C}$ and the frequency ranges from 0.1 to $30 \mathrm{~Hz}$.

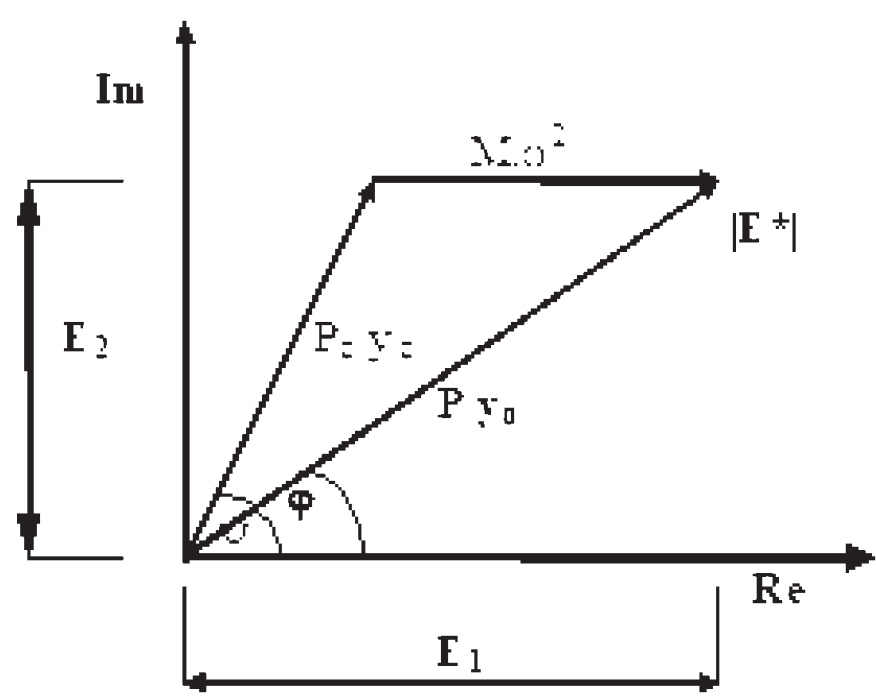

Figure 1 - Complex modulus (Schlosser at. al., 2013)

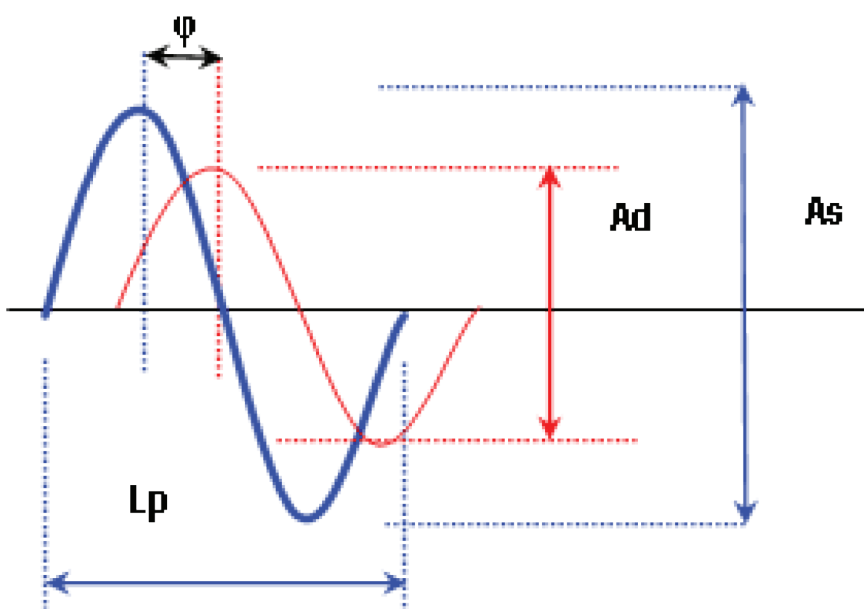

Figure 2 - Measurement of complex modulus (Schlosser at. al., 2013) $E_{1}$ - actual component that characterizes the elastic properties, $E_{2}-$ imaginary component that characterizes the viscous properties, Lp - length of period, $\varphi$-phase-shift, As-amplitude forces; Ad-amplitude deformations 


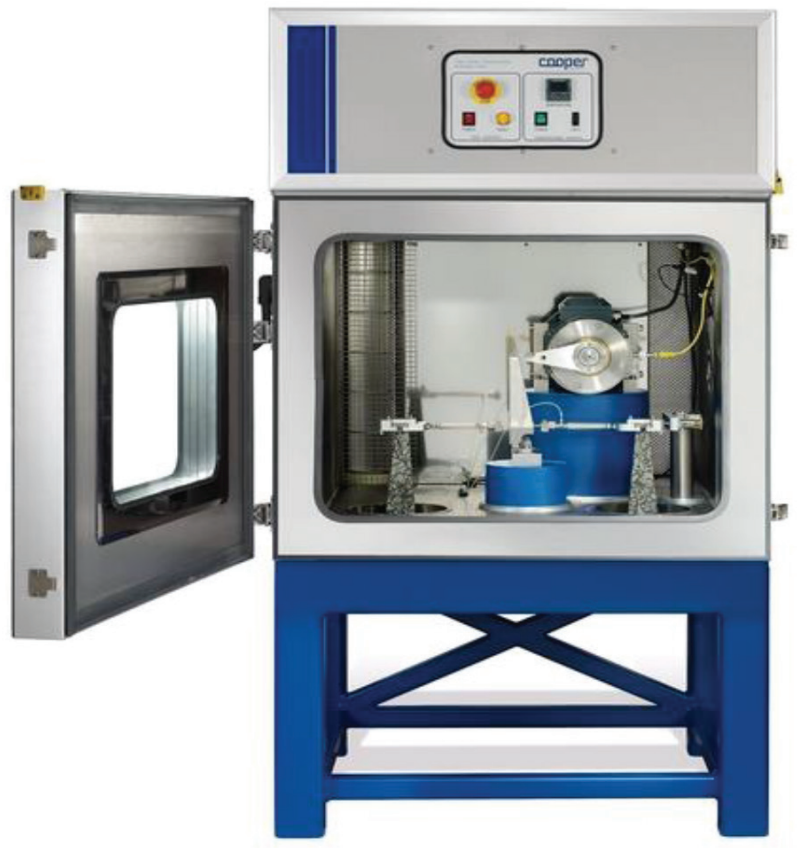

Figure 3: Two-point trapezoidal bending beam machine (Cooper technology, 2017).

\section{MEASUREMENT AND EVALUATION:}

We chose to measure the $\mathrm{AC} 16 \mathrm{~L}$ mixture in two variants (a new mixture with natural materials (M1) and $100 \%$ recycled mixture (M2)). The measurement of the complex modulus was performed at temperatures ranging from $+0{ }^{\circ} \mathrm{C}$ to $+27^{\circ} \mathrm{C}$. The results of the complex modulus for the M1 mixture are in Table 1 and Figure 4 and for the M2 mixture in Table 2 and Figure 5.

Table 1: Complex modulus of the M1 asphalt mixture

\begin{tabular}{|c|c|c|c|}
\hline Frequency (Hz) & \multicolumn{3}{|c|}{ Complex modulus (MPa) } \\
\hline 1 & 7216 & 3022 & 1536 \\
\hline 5 & 8998 & 4217 & 2192 \\
\hline $\mathbf{1 0}$ & 9668 & $\mathbf{4 9 1 9}$ & 2413 \\
\hline 15 & 9916 & 5158 & 2533 \\
\hline 20 & 10326 & 6459 & 2679 \\
\hline Temperature $\left({ }^{\circ} \mathrm{C}\right)$ & 0 & $\mathbf{1 5}$ & 27 \\
\hline
\end{tabular}

Table 2: Complex modulus of the M2 recycled asphalt mixture

\begin{tabular}{|c|c|c|c|}
\hline Frequency (Hz) & \multicolumn{3}{|c|}{ Complex modulus (MPa) } \\
\hline 1 & 9266 & 4320 & 3540 \\
\hline 5 & 9844 & 5246 & 3945 \\
\hline $\mathbf{1 0}$ & 10201 & $\mathbf{6 1 9 2}$ & 4261 \\
\hline 15 & 10763 & 6611 & 4742 \\
\hline 20 & 10908 & 6596 & 5105 \\
\hline Temperature $\left({ }^{\circ} \mathrm{C}\right)$ & 0 & $\mathbf{1 5}$ & 27 \\
\hline
\end{tabular}

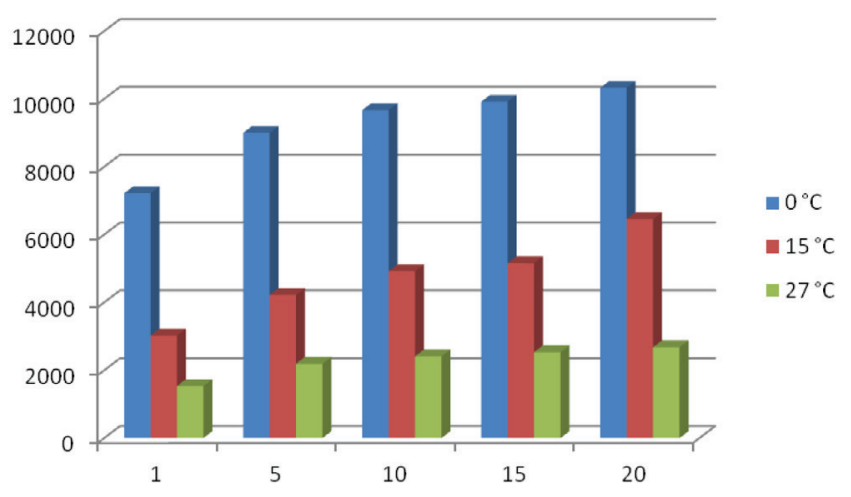

Figure 4: Complex modulus of the M1 asphalt mixture

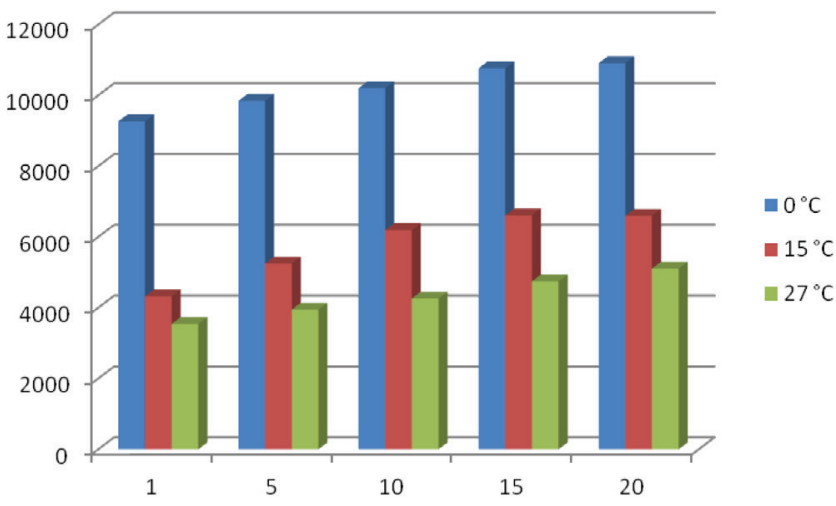

Figure 5: Complex modulus of the M2 recycled asphalt mixture

According STN EN 13 108-1, measuring with a temperature of $+15^{\circ} \mathrm{C}$ and a frequency of $10 \mathrm{~Hz}$ is relevant for classification into categories. The M1 mixture with natural materials is classified in Category $\mathrm{S}_{\min 4500}$, and the $\mathrm{M} 2$ recycled asphalt mixture in Category $\mathrm{S}_{\min }$ $5500^{\circ}$

The results of the measurements of the fatigue with a temperature $+10{ }^{\circ} \mathrm{C}$ and a frequency of $25 \mathrm{~Hz}$ for both mixtures are in Table 3 . The fatigue line (Wöhler's diagram, Figures 6 and 7) is estimated in a bi-logarithmic system as a linear regression of the fatigue life versus the amplitude levels. Using these results, the strain corresponds to an average of $10^{6}$ cycles $\left(\varepsilon_{6}\right)$ and the slope of the fatigue line $1 / b$ (STN EN 12697-24).

The parameters for evaluation of the fatigue are:

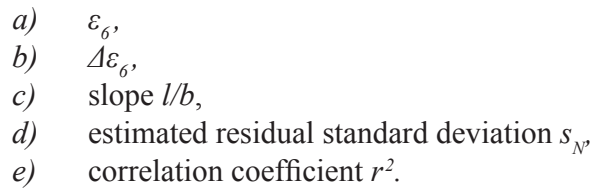

According to the fatigue values (STN EN 13 108-1), the M1 mixture with natural materials is classified in Category Fat ${ }_{\mathrm{e} \text { min220 }}$ while the M2 recycled asphalt mixture is classified in Category Fat ${ }_{\mathrm{e}}$ min115.

\section{CONCLUSION}

When comparing the measured results of the AC $16 \mathrm{~L}$ asphalt mixtures it can be stated that the recycled mixture has about half the resistance against fatigue than that of a mixture made with new natural materials. However, this recycled mixture has higher measured values of the complex modulus of stiffness. According to the results 
Table 3: Fatigue of the asphalt mixtures.

\begin{tabular}{|c|c|c|c|c|c|c|c|c|}
\hline \multirow{2}{*}{ Mixture } & $\mathrm{T}$ & $\mathrm{F}$ & $\varepsilon_{6} \cdot 10^{-6}$ & $\mathrm{~b}$ & $r^{2}$ & \multirow{2}{*}{$\mathrm{sN}$} & \multirow{2}{*}{$\Delta \varepsilon_{6}$} & \multirow{2}{*}{ Category } \\
\hline & $\left({ }^{\circ} \mathrm{C}\right)$ & $(\mathrm{Hz})$ & (mikrostrain) & $(-)$ & $(-)$ & & & \\
\hline AC 16 L - M1 & 10 & 25 & 220.91 & 0.177 & 0.796 & 0.214 & $3.17 \mathrm{E}-09$ & $\mathrm{Fat}_{\mathrm{e} \min 220}$ \\
\hline $\mathrm{AC} 16 \mathrm{~L}-\mathrm{M} 2$ & 10 & 25 & 120.58 & 0.133 & 0.619 & 0.347 & $1.06 \mathrm{E}-09$ & Fat $_{\mathrm{e} \min 115}$ \\
\hline
\end{tabular}

$\begin{array}{ccc}\text { Wöhler's diagram } & y=2 \mathrm{E}-15 x^{-5.638} \\ \mathrm{~T}=10^{\circ} \mathrm{C} ; \mathrm{F}=25 \mathrm{~Hz} & \mathrm{R}^{2}=0.7957\end{array}$

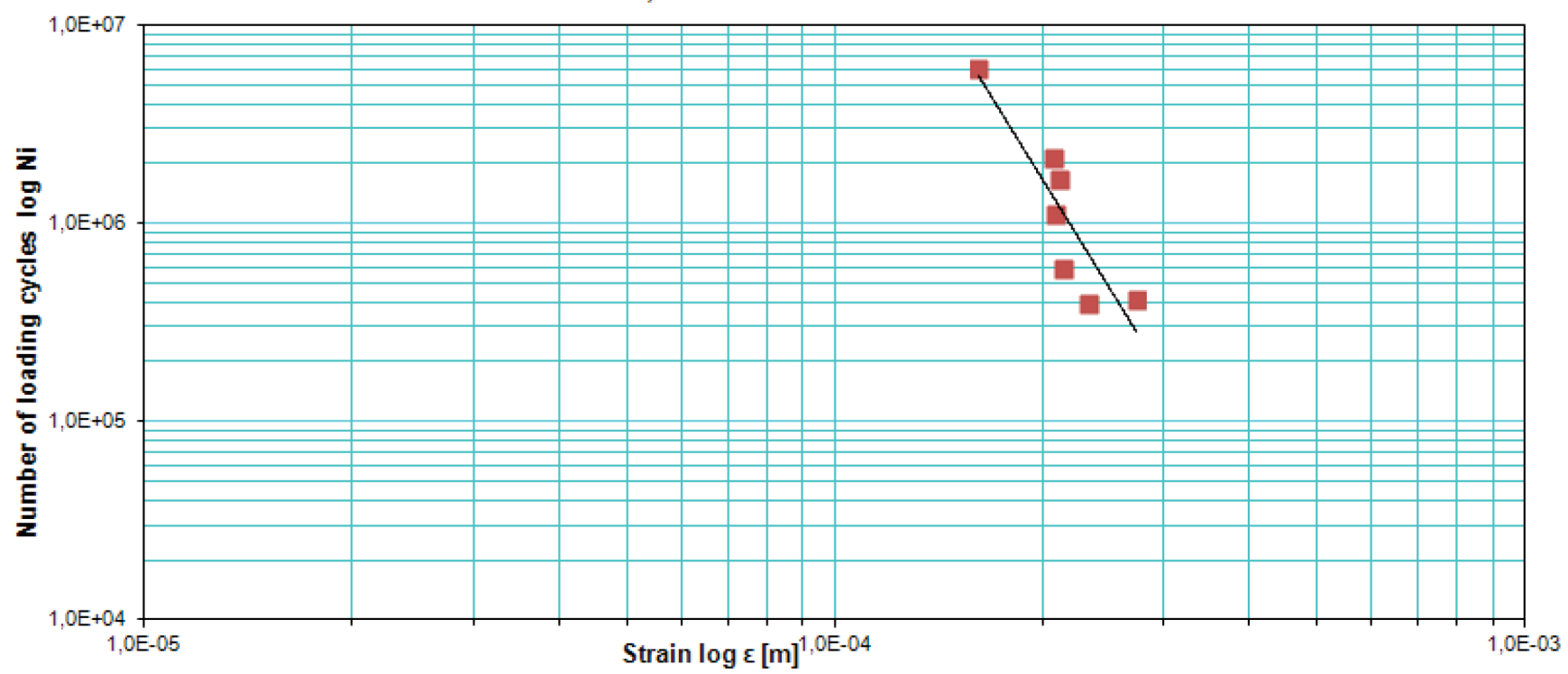

Figure 6: Wöhler's diagram of the M1 asphalt mixture

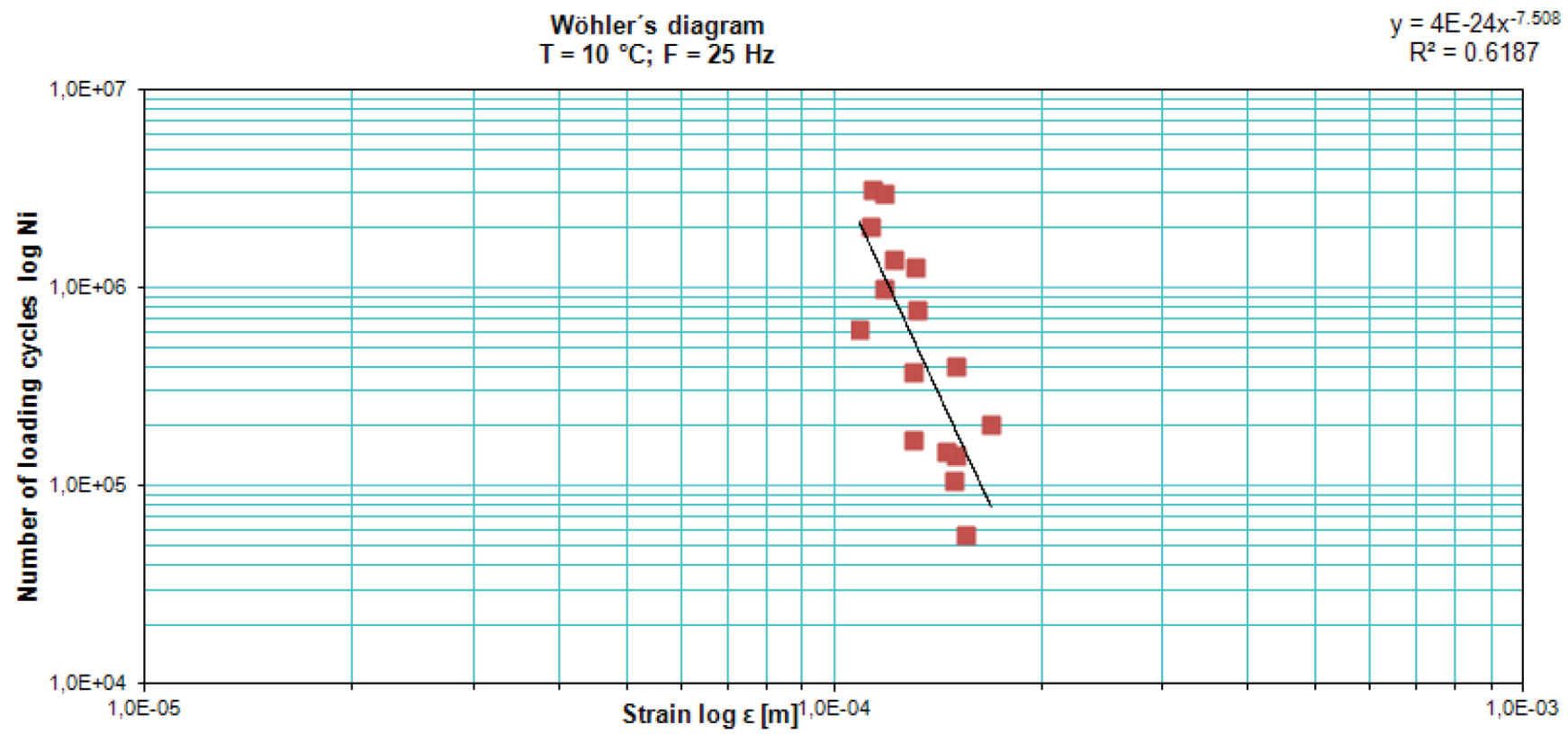

Figure 7: Wöhler's diagram of the recycled M2 asphalt mixture

of the measurements, the recycled $\mathrm{AC} 16 \mathrm{~L}$ asphalt mixture suitable for work activities relating to the maintenance of roads, repair of local defects and repair of asphalt covers. The use of recycled materials protects the environment, reduces the usege of traditional quality materials, and allows more roads to be built or repaired.
From the viewpoint of stiffness and fatigue resistance, the utilization of recycled asphalt mixtures for pavement construction layers is possible, as shown by the results of the measurements. However, it is essential to assess recycled asphalt mixtures and also take into account other properties of asphalt mixtures, e.g. the physical, mechan- 
ical and other properties, in order for asphalt mixtures to be usable in pavement construction.

Stiffness was evaluated following STN EN 108-20 Bituminous mixtures - Material specifications - Part 20: Type Testing, in which is stipulated that the two-point bending test needs to be performed at $15^{\circ} \mathrm{C}$ and frequency of $10 \mathrm{~Hz}$. In conclusion, it needs to be stated that design of asphalt pavements in Slovakia must follow TP 033 Design of asphalt pavements with granular and stabilized sub-grade, in which the stiffness for $0{ }^{\circ} \mathrm{C}, 11^{\circ} \mathrm{C}$ and $27^{\circ} \mathrm{C}$ is stipulated.
It is recommended that the functional fatigue test for of the design asphalt mixtures is used during the design of asphalt mixtures; such a test will determine the life expectancy of the pavement regarding its operational performance. It is important to know not only the proportional strain at 1 million cycles $\varepsilon_{6}$, but also the trend of the fatigue line from the Wöhler diagram for the assessment of mixtures following fatigue resistance. If the trend of the fatigue line is different, it will be necessary to consider which mixture is more suitable for a particular construction layer.

This work was supported by VEGA Project No. 1/0254/15. 


\section{REFERENCES}

STN EN 13 108-1 (2016) Bituminous mixtures. Material specifications. Part 1: Asphalt Concrete (in Slovak)

EN 12697-26 (2012) Bituminous mixtures - Test methods for hot mix asphalt - Part 26: Stiffness (in Slovak)

EN 12697-24 (2012) Bituminous mixtures - Test methods for hot mix asphalt-Part 24: Resistance to fatigue (in Slovak)

Schlosser, F., Mikolaj, J., Zatkalíková, V. Šrámek, J. Ďureková, D. Remek, L. (2013) Deformation Properties and Fatigue of Bituminous Mixtures. Advances in materials Science and Engineering - Mechanical Properties and Nondestructive Testing of Advanced Materials, Hindawi Publishing Corp., Vol. 2013, DOI: 10.1155/2013/701764, Accession No: WOS:000327277000001

Mikolaj, J., Remek, L., Kozel, M. (2016) Optimization of Life Cycle Extension of Asphalt Concrete Mixtures in regard to Material Properties, Structural Design, and Economic Implications. In: Advances in Materials Science and Engineering, Hindawi Publishing Corp., Vol. 2016, DOI: 10.1155/2016/6158432, Accession No: WOS:000385102100001.

Mikolaj, J., Remek, L., Macula, M. (2017) Asphalt Concrete Overlay Optimization Based on Pavement Performance Models. In: Advances in Materials Science and Engineering, Hindawi Publishing Corp., Vol. 2017, DOI: 10.1155/2017/6063508, Accession No: WOS:000411608000001.

Schlosser, F., Šrámeková, E., Šrámek, J. (2016) Rheology, Deformational Properties and Fatigue of the Asphalt Mixtures. In: Advanced Materials Research, Volume 2016, DOI: 10.4028/www.scientific.net/AMR.875-877.578, Accession No: WOS:000339412000108.
Šrámek, J. (2015) Deformation parameters and fatigue of recycled asphalt mixtures. In: Civil and Environmental Engineering, Vol. 11, 2/2015, DOI: 10.1515/cee-2015-0015, Accession No: WOS:000409403600005.

Žák, J., Monismith, C. L., Jarušková, D. (2014) Consideration of fatigue resistance tests variability in pavement design methodology, In: International Journal of Pavement Engineering, vol. 16, no. 1, DOI: 10.1080/10298436.2014.942858, Accession No: WOS:000343298100008.

Remišová, E., Decký, M., Kováč, M. (2014) The influence of the asphalt mixture composition on the pavement surface texture and noise emissions production. In: 14th International multidisciplinary scientific conference SGEM 2014. Geoconference on Energy and Clean Technologies. Conference Proceedings Volume II, 2014, DOI: 10.5593/sgem2014B42, Accession No: WOS:000371090000077.

Ďurčanská, D, Decký, M., Licbinsky, R., Huzlik, J. (2013) Project SPENS - Sustainable Pavement for European New Member States. In: Communications : scientific letters of the University of Žilina. Vol. 15, no. 2, pp. 49-55, ISSN 1335-4205 (Scopus).

Cooper technology (2017) Two Point Trapezoidal Bending Beam Machine, picture available on http://cooper.co.uk/. 